\title{
A Resilience for Survival: Reimagine. Reconfigure. Restart
}

\author{
Martin Deepak Raju Chekuri \\ CF APMP, MBA- Strategic Management, MSc Psychology, \\ Six Sigma Green Belt, Business Proposal Writer, Shipley Associates
}

\begin{abstract}
Governments, Industrialists and CEOs are agreeing that the COVID-19 crisis will impact us way more than the 2008 crisis (Gurnani, 2020). No one really knows how to solve the financial crisis set into motion by COVID-19. Amidst this, there is mounting pressure on sales teams in organisations to sell products and services without sufficient salespeople. To make any sale, or receive funding, organisations go through a process where they must develop a business proposal. Almost no business in the B2B (business to business) market is won without a formal business proposal. Business proposal management and writing has evolved over the years with best practices and certifications, just like project management, but the COVID-19 crisis has given it a jolt unlike any other. Salesteams, bid and proposal management teams. proposal writers and associated graphic specialists need to use this crisis as a catalyst for change. There is a resounding, echoing bell ring that asks us to reimagine, reconfigure and restart. And the bell does not ring just for teams but also for individuals. The future depends on interactive technologies and proposal teams must think about playing strategic roles if they want to stay relevant. For the investigation and writing of this paper, we have used both primary and secondary research techniques. They are listed as follows: Primary Research - Questionnaires and Interviews; Secondary Research - Journals, Harvard Business Review, Economic Times, Internationally acclaimed websites, Textbooks
\end{abstract}

Keywords: Sales, Presales, Bid Management, Proposal Management, Strategy, Marketing, Change, Change Management, Future, Collaboration, Virtual Teams, Design, Automation

\section{Introduction}

The word "thrive" has taken backstage, at least for now. Right now, organisations need to have a plan to survive. No one in an organisation can get comfortable in their cubicle chair and let their world spin on autopilot. With a crisis looming that is greater than what we faced in 2008, resilience is key. Reimagining the way we do things, reconfiguring the way we work and restarting our business with a fresh outlook is the order of the day. It may be the only way for organisations to survive this dark phase of human history.

\section{Scope of The Research}

The scope of this research is limited to organisations which have turnovers of over a million dollars and range upto several billions (USD). All of them are B2B. These huge organisations 
and the people they employ have a direct impact on how governments operate and international trade across the world runs.

Considering the COVID-19 crisis, it is important that these organisations generate sales, and convince their customers to make purchases in order to restart the global economic cycle.

\section{Trends Proposal Teams Are Expressing}

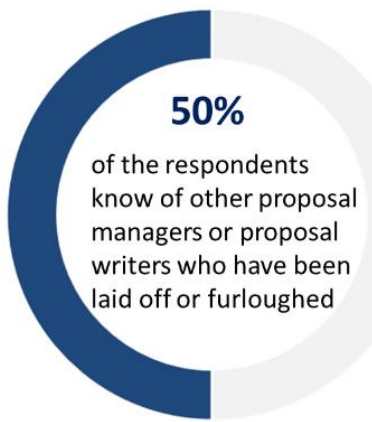

Figure 1: COVID-19 has brought gloomy days to proposal teams

For an industry to not be affected by the COVID-19 scenario is a pipe dream. Despite organisations having risk-mitigation plans, due to crises as tremendous as COVID-19, they began laying off employees.

Sales and presales teams in most industries and companies have dramatically dwindled. However, there is an undeniable demand for someone in the organization to write proposals. This brings us to two frequently asked questions.

What are business proposals?

What makes them so important?

\section{A Brief Introduction to RFXs and Business Proposals}

Customers send a document with a thorough list of requirements to multiple vendors. This document is called the RFX. The X can be replaced with alphabets such as I, Q and P.

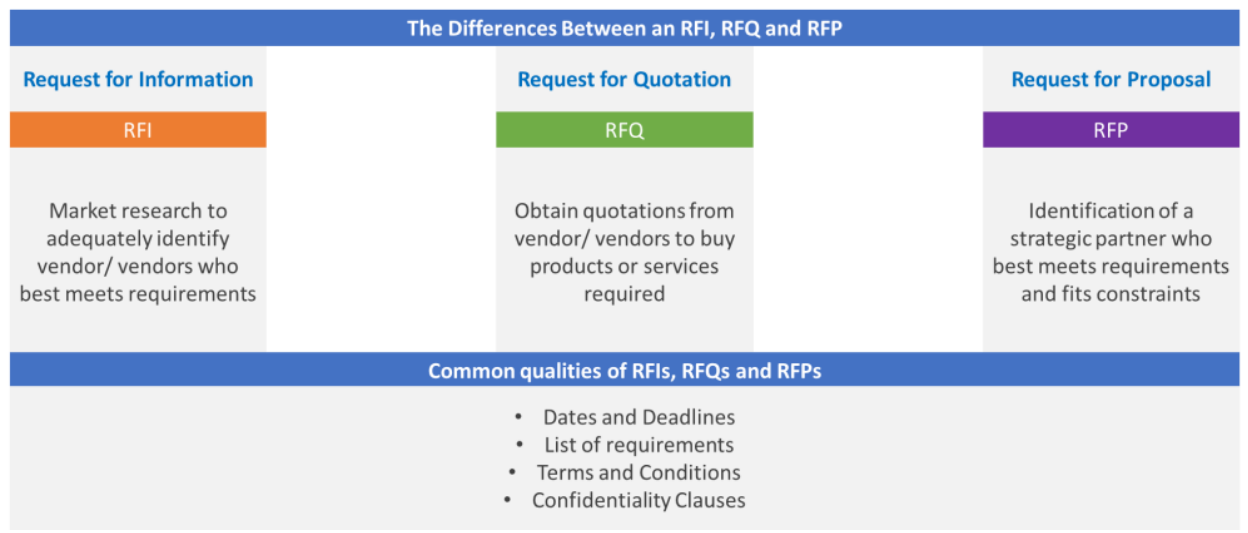

Figure 2: What are RFIs, RFQs and RFPs? 
Customers send a document with a thorough list of requirements to multiple vendors. This document is called the RFX. The X can be replaced with alphabets such as I, Q and P.

While vendors find it hard to respond to RFPs, customers find it equally hard, if not harder to create RFPs.

Once it arrives, sales teams immediately try to gather information about the customer. They try to identify if the customer already has a favourite, or an incumbent vendor- who is currently supplying the product or service.

Then, they prepare the response document, also called a proposal. A business proposal is light years away from a marketing brochure. It is customised to the customer's needs. At its heart, it understands that customers do not care about vendors, their products or their services. Customers care about themselves.

Without doubt, consistently winning proposal teams are doing something radically different from their competition's proposal teams.

\section{Proposal Strategy}

Outline: "Hope" is never a strategy while creating a business proposal. At least, having an idea of the customer's needs, issues and motivators and identifying sponsors helps create a better strategy. Identifying the degree of competition and therefore developing partnerships gives organisations an extra edge. Proposal teams must work with agility and steadfastness to beat the clock in order to achieve this.

Getting all roads to lead to Rome: Proposal teams manage various meetings- the first being the kick-off meeting- where everyone is introduced, and everyone's goals and roles are set. Most importantly, the due dates are discussed, and a thorough plan is developed by the proposal manager that gets everyone to contribute and complete the RFP response.

RFPs are hot potatoes: RFPs can be several hundred pages long. Getting even one of the terms and conditions, or making a wrong observation can cause the organisation to lose the deal, or worse, cause the organisation to get into legal and financial obligations.

Troubles shared are troubles halved: There can be anywhere between three (3) to three hundred (300) people involved in responding to an RFP depending on its deadlines, value, risk and complexity. Proposal teams assist technical teams in conveying their message to the customer in a clear, succinct, attractive, legally accurate and time-bound manner to ensure organisations win more business.

\section{How Important Is a Proposal?}

Proposals are worthless unless they induce a behavioural change in the customer. It is meant to woo, not repulse. It is meant to impress, not bore. It is meant to cause a desire that otherwise was not there.

Hence the name "proposal". It needs to be sought after. It needs to be something the customer wants, not just needs. It needs to be loved. Every page should trigger a sense of anticipation.

How proposals are written is just as important as what is written in them. 


\section{How has COVID-19 Impacted Proposal Teams}

Proposal teams are being laid-off, furloughed, or are taking pay cuts in many organisations that are not seeing business opportunities. The work of proposal teams is being passed on to delivery teams in order to reduce costs in these organisations.

However, a few organisations from industries like pharmaceuticals, telecommunications, medical device manufacturing, are growing in these times. Proposal teams are being hired by them.

\section{Collaboration Has Never Been a Problem}

Proposal Teams, COVID 19 and Work From Home Policies

$80 \%$

8 out of 10 individuals were used to working from home and hence quickly adapted to the change

Most organizations have liberal work from home policies that are exclusive to their proposal teams

Figure 2: What are RFIs, RFQs and RFPs?

Global collaboration has dramatically increased across organizations in all teams by over $1000 \%$ (Samik Roy, 2020). Although other teams across the world have been shaken up by new work-from-home norms, most proposal teams have reported that there is almost no difference in how they worked.

Proposal teams can continue to work-from-home unless of course, it is crucial for a major deal that requires war-rooms. Today, even those can be virtual. However, we only recommend that cameras be turned on so that the human element is not lost.

\section{Survival of the Fittest}

To adapt to COVID-19, some organisations have committed to not lay-off their proposal management teams or change processes. However, most organisations have realised that they might need to shift their modus operandi to a way of work that would continue to keep the company profitable. The ultimate way to win this battle during this crisis is to find solutions and techniques that will:

- $\quad$ Focus on strategy and competitive advantages (offer something unique to customers)

- Develop better partnerships with other organisations

- $\quad$ Reduce costs by reducing employee headcounts and/or remunerations 
- Increasing revenues by responding to more RFPs in less time

- $\quad$ Exploring new markets

- Improve effectiveness and efficiency > Bring in automation, tools and techniques

- $\quad$ Reimagining Proposal Management and Sales

\section{Case Study}

Christopher (name changed) has about twelve proposals he was working on simultaneously. Only one of them is winnable and no one is working on it.

The multi-million-dollar company Christopher worked for, faced a massive blow due to the COVID-19 crisis. $60 \%$ of their clients were from the tourism and travel industry. As a result, the organisation went into panic mode. They tried to get their hands on every single RFP available- even if they had very limited chances of winning it.

Because of the ensuing crisis, a few proposal managers, writers and graphic designers were laid-off. The graphics team predominantly prepared customised content that clients would find relatable

Suddenly, Christopher's laptop crashed. Along with it went all the information that went into the proposal. Some of the information on the laptop was not saved on the cloud and was not passed on to any team members.

Two candidates who contributed to the proposal had left the organisation. Although their data backup was taken, no one knew how to find it and re-assemble it at such short notice. Christopher now is unable to find the information he needs the most.

Suddenly, an entire proposal had to be built from scratch. With just five days left to submit the proposal, Christopher's fingers tremble, as he visualises incoming migraines. With a cold sweat breaking, Christopher empties a cup of coffee each hour to stay awake. Panic escalates into horror.

He enlists the help of another overworked proposal writer who is based out of a different timezone to review the styles, fonts, themes and colours. He gets a graphic designer who already has a plethora of work to cater to and pleads with him to create a cover page. The graphic designer tells him he cannot do it and suggests that Christopher can choose from a set of previously created cover pages.

Christopher does the best he can, with the resources he has. And in five days, he submits the proposal to the customer after getting a review done.

The proposal goes to the customer and Christopher finally goes to bed. Barely a minute after he has hit his pillow, he gets a call from his manager telling him it is urgent. He shows Christopher that in several places of the document, there is the name of the wrong client- an indication that sufficient attention has not been paid. In the proposal world, that mistake is a monstrosity. It happened because Christopher copied the content from other proposals he could find. He pasted it without thoroughly checking its relevance.

And then his manager shows him that some content that was placed is old and there is new, better and more mature content available from a technical and a non-technical point of view. Literally, the proposal is a piece of trash. Every single minute spent on it amounted to nothing. 
From a graphical point of view, there is nothing that tells the customer that Christopher's proposal was crafted with professional intent. Christopher was forced to focus on submitting the proposal. He did not have the time, nor the resources to win it.

Christopher was living Murphy's law: "Anything that can go wrong- will go wrong"

\section{Strategy 1: Bid to Win. Not Just Submit}

Christopher's organisation was trying to grab every opportunity they got to stay afloat, instead of focusing on the one they could win. Also, Christopher was an overworked, confused, and unrested proposal manager who was working without the support of a team. A recipe for disaster- it has been proven, tried and tested that none of these strategies work. It results in limited organisational focus and excessive organisational chaos.

To solve this conundrum, organisations must, at the least, ask themselves the following questions before opening up RFPs and sending them to proposal managers to work on:

Is this within our business area?

Does the customer really intend to buy?

Do we know the customer and the customer's vision?

Have we considered the global crises that can prevent this purchase?

Is there an incumbent who the customer is not satisfied with?

Do we have any competitive advantages that our competition does not possess?

Do we have any competitive disadvantages that we need to tactically manage?

Is there a risk we face if we bid / do not bid for this opportunity?

Can we really win? How and why might we lose?

Is the pursuit worth the effort?

In times like these, sales-persons may be tempted to hunt for any opportunity available. However, a thorough bid validation must be done before engaging proposal teams on a deal, lest it waste their time and wear them down.

When they get involved, proposal managers must be able to showcase compliance rather than finding reasons for non-compliance to customer requirements. They must be able to show an understanding of the customer's pain points and motivation to spend money despite market conditions

\section{Strategy 2: Make Proposals Sing}

In his bestseller entitled "Epic Content Marketing", Joe Pulizzi asks, "Your customers are exposed to over 5,000 marketing messages per day. Are your messages cutting through the clutter and making an impact?" (Pulizzi, 2014) Although Pulizzi is talking here about content marketing, one can extend his theory to proposals. With all the clutter of information, will your message matter?

In another study (Nicholas Toman, 2017), where several thousand executives at companies across the world were asked to describe the entire purchase process, out of which, obviously, 
reading RFPs from multiple vendors and coming to a conclusion would be one. Some responses included "hard", "awful", "painful", "frustrating" and "minefield".

In a world where 140 characters is all one gets to convey information that is meaningful (Twitter), proposal contributors must aim to keep their messages as short and simple as possible.

\section{Keeping it Simple}

Proposal Teams ought to take the effort needed to make the proposal a joy to read. And yet, almost no proposal evaluator would express that reading proposals is a pleasure, or a joy. Instead, proposals are pompous and boring. Evaluators seldom find them engaging and feel like they are not tailored for them and are corporate mumbo-jumbo.

Proposal contributors are under the impression that a lot of information on a subject will impress the customer. One study (Nicholas Toman, 2017) points out that customers are increasingly overwhelmed and often feel paralysed than empowered by information overload. Information overload births unnecessary questions, inquiries and probes. This causes a $65 \%$ delay in purchase decisions, and often, deviations towards other sellers / vendors. Clearly, proposal contributors must learn to respect the time of evaluators.

\section{The Impact of Good Design in Proposals}

A business proposal is like a salesperson. It cannot afford to be shabbily dressed. It is crucial that the first impression be good. People think that they are not bewitched by first impressions, but that is not true. Hence, graphic design is becoming extremely important.

\section{Proposal Teams and Graphic Design}

$92 \%$

$92 \%$ of our respondents say that they use documents or slides to prepare proposals



When asked to rate the importance of good graphic design, nearly $80 \%$ of respondents rated it "extremely important"

Figure 2: The Impact of Graphic Designers

Although the famous idiom goes "Do not judge a book by its cover", several studies found that people make judgements about the quality of the content in a book by looking at the cover page in just about five seconds. In fact, there are so many proven logical fallacies that the human brain is prone to make based on design such as: 
Implicit Association Bias: Just because something looks good, we assume it is good.

Von Restroff Effect: When multiple options are present, attention is subconsciously directed towards the one that stands out.

Law of Triviality: We tend to spend time on trivial, good-looking things- whether or not they are important or are serving our purpose.

\section{The Future of Proposals}

Organisations are realising that they need proficient graphic designers to design proposals for them. There are huge indicators of how important graphic design is and how dependent the proposal teams are upon them.

In a world where everyone is using documents and slides, there are organisations which are silently moving towards software and web applications that are far more effective and engaging.

For nearly twenty years, Microsoft's PowerPoint and a few other similar tools have been used to create customer pitches. Multiple presentations attached in a single email, confused evaluators and waste their precious time, thereby sometimes annoying them.

But things are changing. LinkedIn's PointDrive, for example, is changing the way presentations are done. Instead of making content static, it is making it dynamic. Evaluators are also more inclined to read content sent to them via PointDrive is because they can interact with content on any device. From a proposal author's point of view, PointDrive allows them to see which content has been most interacted with. (Burnett, 2017).

PointDrive, and similar tools are already being used to submit proposals. In fact, organisations have started presenting proposals based on augmented reality and virtual reality.

In a world where people prefer engagement, why would anyone want to read? That is why UI (user interface) and UX (user experience) is becoming important. We anticipate UI and UX being given a colossal importance in the future. We have already seen how much importance organisations are giving graphics teams.

We recommend that graphics teams learn more skills and upgrade themselves. At least, they must be able to make customised video presentations and have an idea of how augmented reality and virtual reality works, and what tools can be used to prepare futuristic presentations.

Under anonymity, one proposal manager we interviewed, explained how the organisation he is working with is currently crafting presentations that are designed for presentations on Zoom, GoToWebinar, Skype or MS Teams. "Each platform works differently and streams content differently. So, we design presentations based on the platform. We do not do that for every deal, but we are getting there. We realized that things do not look the way we intend them to look if we do not know the platform they will be streamed on. Customers are beginning to tell us that there is a noticeable difference, and that our presentations look better than our competitors' presentations", he said.

$87.5 \%$ of our respondents agreed that proposals need to be designed in a manner that needs as little explanation as possible, with minimalism and engagement. 
Owing to the COVID-19 crisis, no presentation is being made at the customer's office. Even if a video presentation is recorded, because of its length, customers are not willing to watch them. That is why, the proposal presentations being sent to them must be engaging and interesting enough for evaluators to want to go through them. For this too, a graphic designer supplies life blood.

\section{Strategy 3: Exploring Automation}

The word often instils fear and paranoia. According to many, it is a necessary evil, which feeds corporate greed. However, history has proven that whenever automation came, it led to the loss of a few jobs but created several thousands, if not millions more. However, if the question is "will automation take away my job as a proposal manager or a proposal writer?", the answer is most likely "yes".

Proposal managers, for example, need to coordinate a proposal from end to end- which includes not just ensuring compliance, but preparing the proposal, getting proposal contributors to update content, making calls to get information, managing proposal playbooks and getting approvals, to name a few

For example, Amjad and Samina, based out of Maryland, USA are creating a futuristic RFP tool called Zbizlink. The tool can almost effortlessly improve the speed of proposal processes three times over by helping managers. It automatically pulls out requirements from RFPs. It also helps managers create workflows, plug in content, manage collaboration and do a whole host of other things- all over one web-based application that can be accessed both on the proposal teams' laptops and mobile devices.

When it comes to proposal writers, there are tools already available that radically improve the proposal's quality, tone, professionalism and uniformity. Another huge problem that writers face is the famous "writer's block". There are automation tools, which, when fed with bits and pieces of necessary information, literally write content. Shipley ROSE for example, helps proposal authors write anywhere between $50-70 \%$ of the executive summary within just ten minutes

We are already seeing automation technology enter the proposal management space helping proposal teams. Instead of asking what automation will take away from us next, we need to ask what work automation will enable us to take on.

\section{Content Management}

In organisations where content is diverse and solutions are aplenty, it is important to appreciate and make way for a proper content management system. It is a terrible idea nowadays to maintain all content on a few computer devices or dump content onto a server.

In our survey, 31 out of 40 respondents said that they had some form of organisational content repositories. Among them only 7 had automated content repositories that would use metadata to identify content. In fact, very few organizations have heard of AI driven content management solutions. But they are out there.

Organisations that have systematic content management repositories and teams, also express a greater degree of success. Out of the 40 respondents we interviewed, there were 33 respondents who had content respositories. This meant that they recognized its importance. However, they did not have content management tools and did not invest into content 
management teams. They expressed having often used old and irrelevant content and were able to trace it back to not being able to find the right content at the right time.

\section{Do you use content management tools and centralised content repositories in your organization?}

Answered: 40 Skipped: 0



Figure 3: How Teams Are Managing Content

At the least, organisations should attempt to organise data on the cloud- where content would be accessible and retrievable with minimal downtime.

Established organisations have content management teams who curate content and upload content onto the cloud. Better still, they do this using tools that manually or automatically absorb metadata that is tagged to the document. This allows proposal teams to find what they want, when they want it, without having tunnel vision or slowing down. They will have the most recent content that has been curated and pre-approved.

Like other aspects of business, knowledge and content management is moving from traditional human input towards artificial intelligence that reads a document and automatically identifies metadata tags.

This enables proposal teams to be more than cut-copy-paste artists. This gives them time to become strategists, wordsmiths and artisans in their field.

A good content management strategy is not just something "nice to have". It must become an integral component of the proposal management team's armour. It is an incredibly important component of the proposal management team's battle gear when they go to war. Is it expensive? Maybe, yes. But going to battle without it might result in severe damages to reputability, credibility, and reliability in the eyes of the customer.

\section{Reconfiguring Proposal Management}

\section{Case Study}

Typically, customers could not read a proposal that came from the company where Christopher worked without yawning incessantly. Most of them never got to the last page. Although Christopher's boss got feedback regarding the kind of proposals that went out, he never found enough time to take a stab at them and improve them. 
With the advent of COVID-19 however, everyone woke up. The senior management wanted to see more deals being won. Christopher and his boss had to get their act together or bid their jobs goodbye.

\section{Strategy 1: 4 Step Improvement Model}

Although the COVID-19 crisis is not exactly a crown, it certainly does come with some silver linings. One of them is that organisations are not getting many RFPs to work on. The time could be used for process improvement and eliminate operational waste. There are organisations where for several years, the proposal team has been static with no one looking into the modus operandi- as a result of which, the organisation is not able to open up to its market potential.

We recommend that if organisations find a little extra time, they should not waste it. They must improve their processes, and align themselves with the vision of becoming leaner, stronger organisations. It goes without saying that organisations must do what is necessary without causing any major business disruption.

Proposal teams can follow the proven "Four Stage Model of Operational Improvement". The model was developed by Professors Hayes and Wheelwright of Harvard University with contributions from Professor Chase of the University of California.

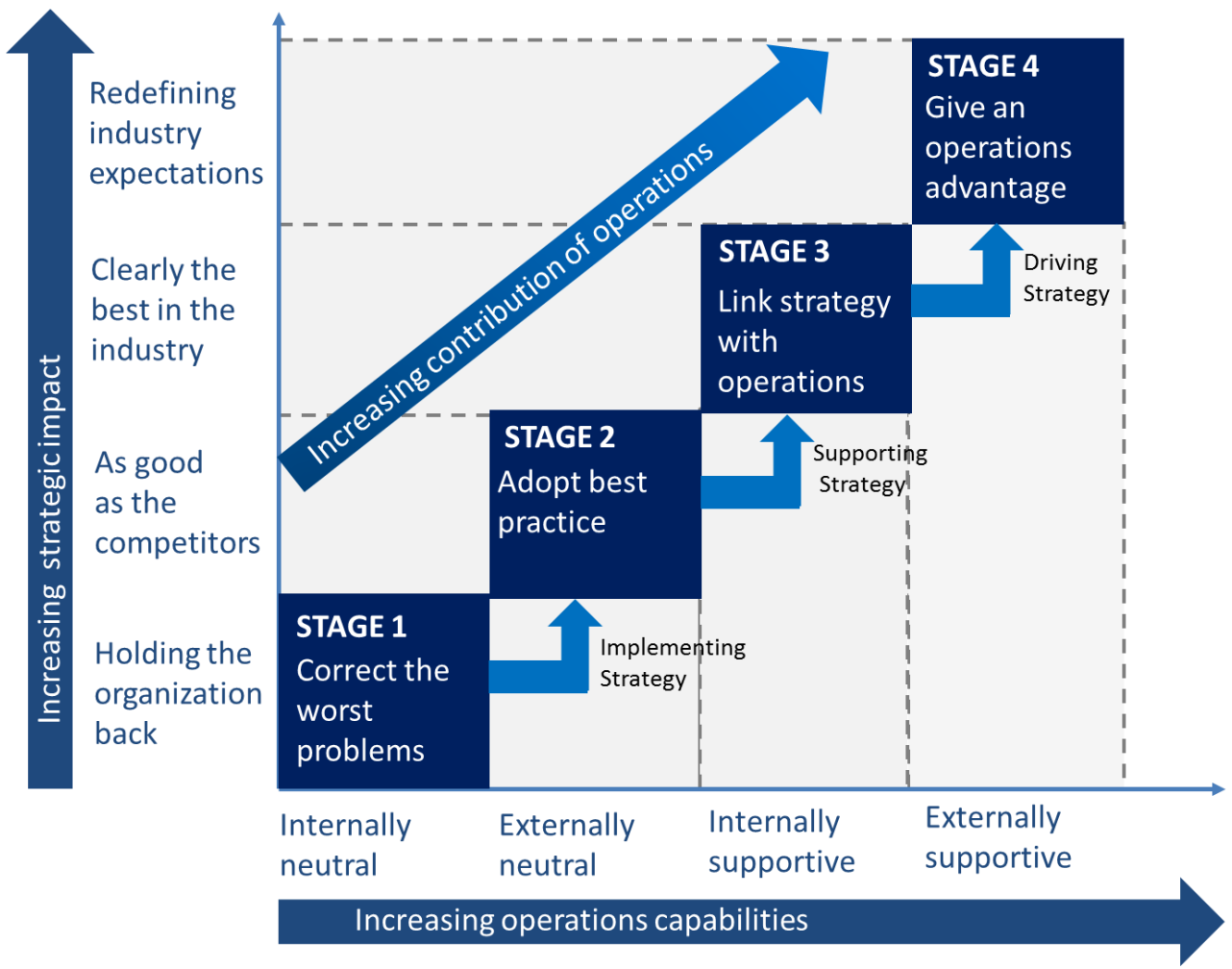

Figure 4: The Four Step Model for Operational Improvement

During Stage 1, the proposal team may identify the top three most pressing issues and worst problems they face and use a systematic approach to solving them. Do not go after small 
problems. Try identifying problems within the team which are causing genuine pain to the business. The goal is to fix those pains.

During Stage 2, now that the team has fixed the worst problems, the team works towards industry best practices. This may include adopting unexplored and relevant APMP best practices for proposal management, reviews, improving quality of executive summaries, and improving content repository capabilities. The goal is to be as good as the competition.

During Stage 3, the team develop strategies on becoming industry leaders on how proposals can be written. A simple example would be adopting tools and techniques and develop guidance tools that will assist proposal contributors avoid writer's block. There are so many tools available in the market that can and help write better proposals and present them to customers in a more professional manner. Tools like Shipley ROSE for example, helps proposal contributors write anywhere between $50-70 \%$ of the executive summary within just ten minutes. The goal in stage 3 is to become better than the competitors.

During Stage 4, the team starts preparing for the next global crisis or the next big scenario that is going to hit their industry; and works towards staying one step ahead of the competitors. Simply put, the goal in stage 4 is to identify the trends of the future before they come and stay prepared.

\section{Strategy 2: Create Compelling Content}

A great way to improve a team's proposal writing skills and increase the win ratio is to teach them the art of persuasive proposal writing. HBR recommends using the Who-Why-WhatWhen-How chart (Garner, 2012)

This need not be just for content written afresh, but for boiler-plate content already present in the organization's repositories.

Additionally, we recommend the following steps to creating persuasive and profession content:

Step 1: Asking the question, "Why write this?" before composing content in any section. helps instil the necessary tone, morale and pace, thereby reaching the goal of the proposal.

Step 2: Avoid verbose content, jargon, convoluted sentences and paragraphs that instil boredom in the reader. Understand that poorly written content is a huge waste of the reader's time. If writers do not get to the point quickly enough, the reader might switch-off. Be relentless in achieving this

Step 3: Use tables and graphics to keep the proposal engaging. Use them to illustrate something discussed in the text. The goal is to help readers understand in 4-5 seconds via pictures what would take 2-3 minutes to read

Other strategies that would dramatically improve the persuasiveness of proposals include:

Using the customer's name more frequently throughout the proposal

Quantifying benefits of the solution

Keeping the most important ideas first while writing content.

Helping customers perceive differentiators and discriminators. 
Composing headings that guide readers rather than using abstract headings.

Adding graphical inputs (such as call-out boxes or figures with action captions) aids readability and increases customer interest.

"Make It Easy" Policy

Business proposals are often written by technical teams, who tend to pay less emphasis to strategic details- which help win more business. They often state the features of the product, rather than the "benefits" and "advantages" that customers gain when they purchase them.
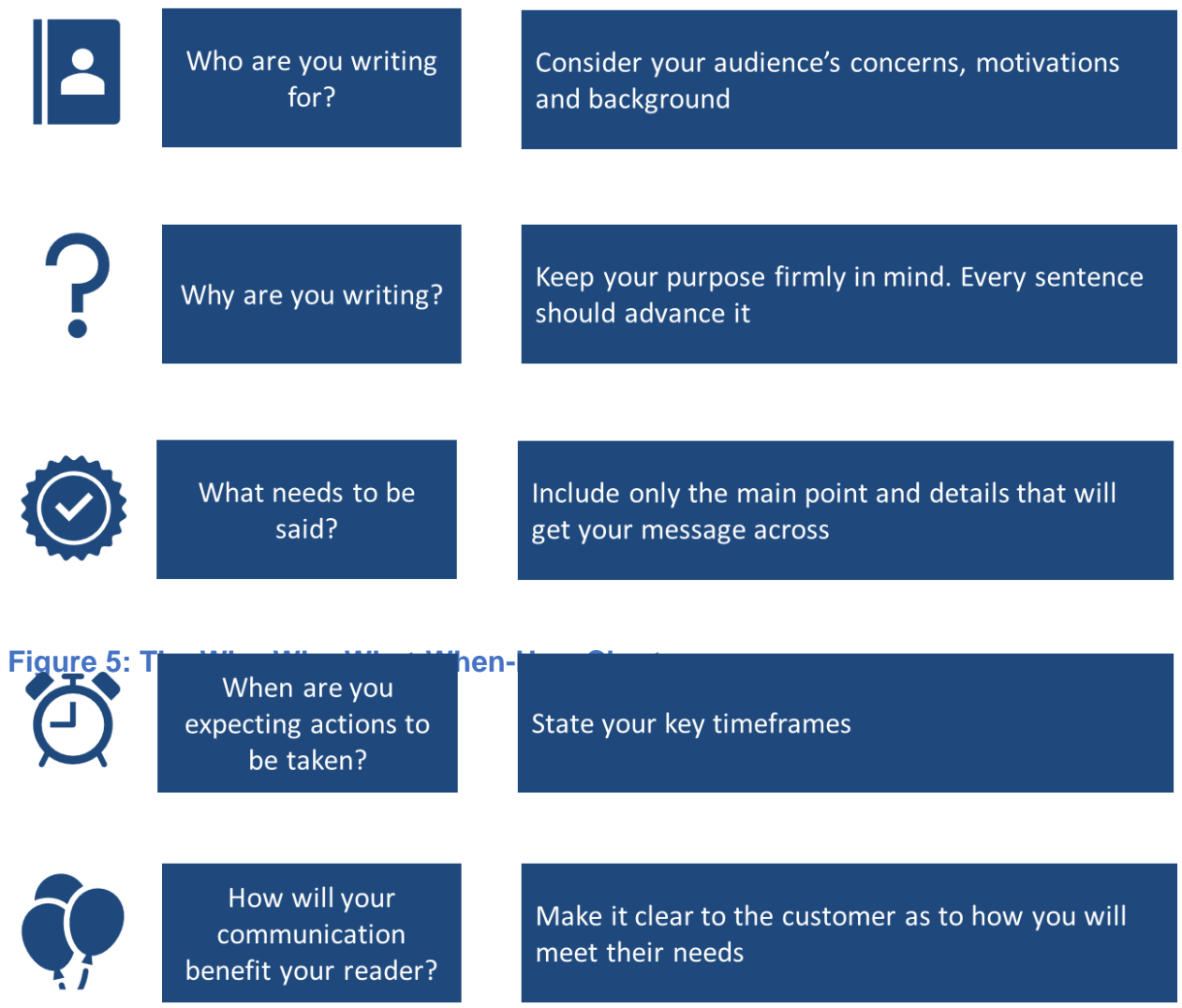

Make it clear to the customer as to how you will meet their needs

Benefits and advantages are compelling, but customers are not persuaded enough to purchase products if these "advantages" are not shared with them. It is crucial that proposal authors make it a point to articulate benefits throughout the proposal.

Consider the following statements.

Statement 1: The laptops come with inbuilt 8GB RAM

Statement 2: The laptops come with in-built 8GB RAM - which allows you to work faster and lessens the scope of the laptop crashing by $35 \%$ 
The statement above in italics helps customers identify benefits rather than just providing them with features

The Shipley Proposal Guide says, "Benefits have the strongest and most lasting impact on customer decisions as they are explicitly linked to alleviating issues. In short, customers buy benefits." (Newman, 2016)

\section{Differentiators and Discriminators}

Organisations need to be more intelligent in how they sell. Often, proposal teams do not have sufficient input on the strengths and weaknesses of the organization's competitors.

Amongst those that understand the competition, most proposal contributors focus on differentiators, and not enough on discriminators. Differentiators are what make organizations different from their competitors.

Discriminators, on the other hand are differentiators that can be acknowledged as important to the customer.

Additionally, proposal teams must deal with a proposal's weaknesses.

If competitors can articulate features that are beneficial to the customer, which the proposal does not provide, they become negative discriminators and proposal teams need to examine addressing the issue in their proposals.

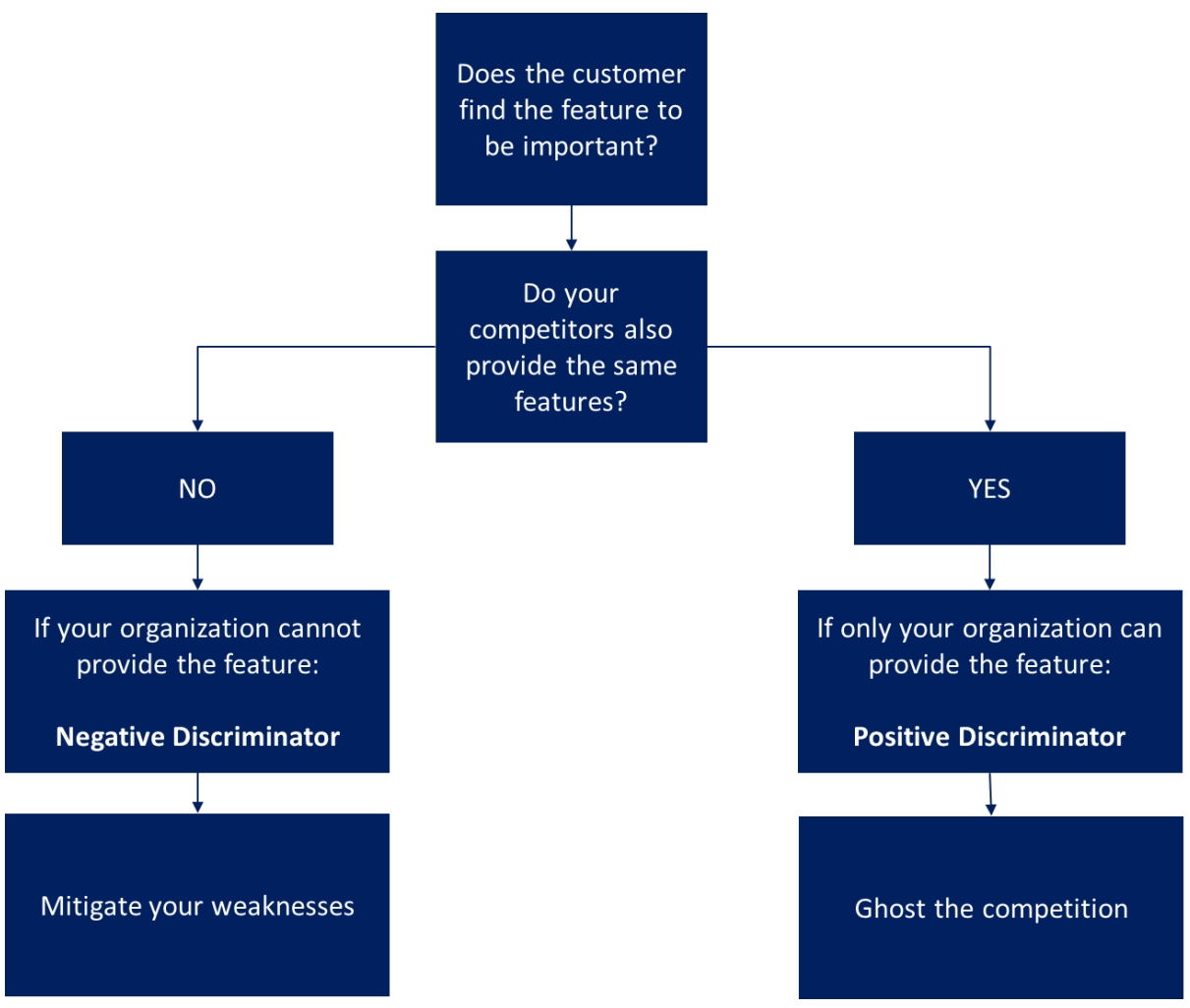

Figure 6: Understanding Discriminators 


\section{Proof Points}

While being customer focused, proposals must include relevant referrals and case studies. This helps prospective clients gain more trust that the proposal is more than just a can of empty words.

\section{Strategy 3: Change Management}

People get into a rhythm that makes them resistant to change. To understand the mindset, try changing hands when you brush your teeth in the morning-Gary Gesme, Deere \& Company

Studies show that anywhere between $70 \%-80 \%$ of change efforts flop. They either fail to deliver the anticipated benefits, or they are abandoned entirely. (Steven H Appelbaum, 2012)

Before proposal teams work towards radical shift in how operations are run, they should spend time studying them. Do they really need to be improved?

A frequent adage at a multi-billion-dollar organisation goes "In our organisation, change is the only constant". While that might be true, organisations must not make changes that are so dramatic and frequent that chaos would ensue.

The catalyst for change must be the pursuit of value. If there is no tangible value that change would bring, organisations must not pursue radical changes.

According to Kotter, the eight steps to transforming an organization (which can be applied to proposal teams) are:

Establish a sense of urgency about the need to change because people will not change if they do not see the need to do so.

Create a guiding coalition- assemble a group of individuals who have the power, energy and influence to lead the change.

Develop a vision and a strategy. Create a vision of what the change is about. Tell people why the change is needed and how it will be achieved.

Communicate the change vision - tell people, in every possible way and at every opportunity, about the why, what and how of the changes.

Empower broad-based action - involve people in the change effort, get people to think about the changes and how to achieve them rather than thinking about why they do not like the changes and how to stop them.

Generate short-term wins - seeing the changes happen and recognising the work being done by people towards achieving the change is crucial.

Consolidate gains and produce more change - create momentum for change by building on successes in the change. Invigorate people through the changes and develop people as "change agents".

Anchor new approaches in the corporate culture - this is critical to long-term success and institutionalising the changes. Failure to do so may mean that changes achieved- through hard work and effort, slip away with people's tendency to revert to the old and comfortable ways of doing things. 
Through a process of change, proposal team members' responsibilities are being increased or altered in order to win more business. There is nothing wrong with this. It just needs to be systematic and not an act birthed out of panic.

Efficiency is doing things fast while effectiveness is doing things right. We see proposal teams pursuing value, often focussing on efficiency and not on effectiveness. Organizations can pursuit change but ensure that it does not hamper the effectiveness of proposal teams.

\section{Preparing for Changes}

Before changing a process, tool or policy within the proposal teams, we recommend that teams develop clarity by using the following screens (Slack, 2009)

Restarting

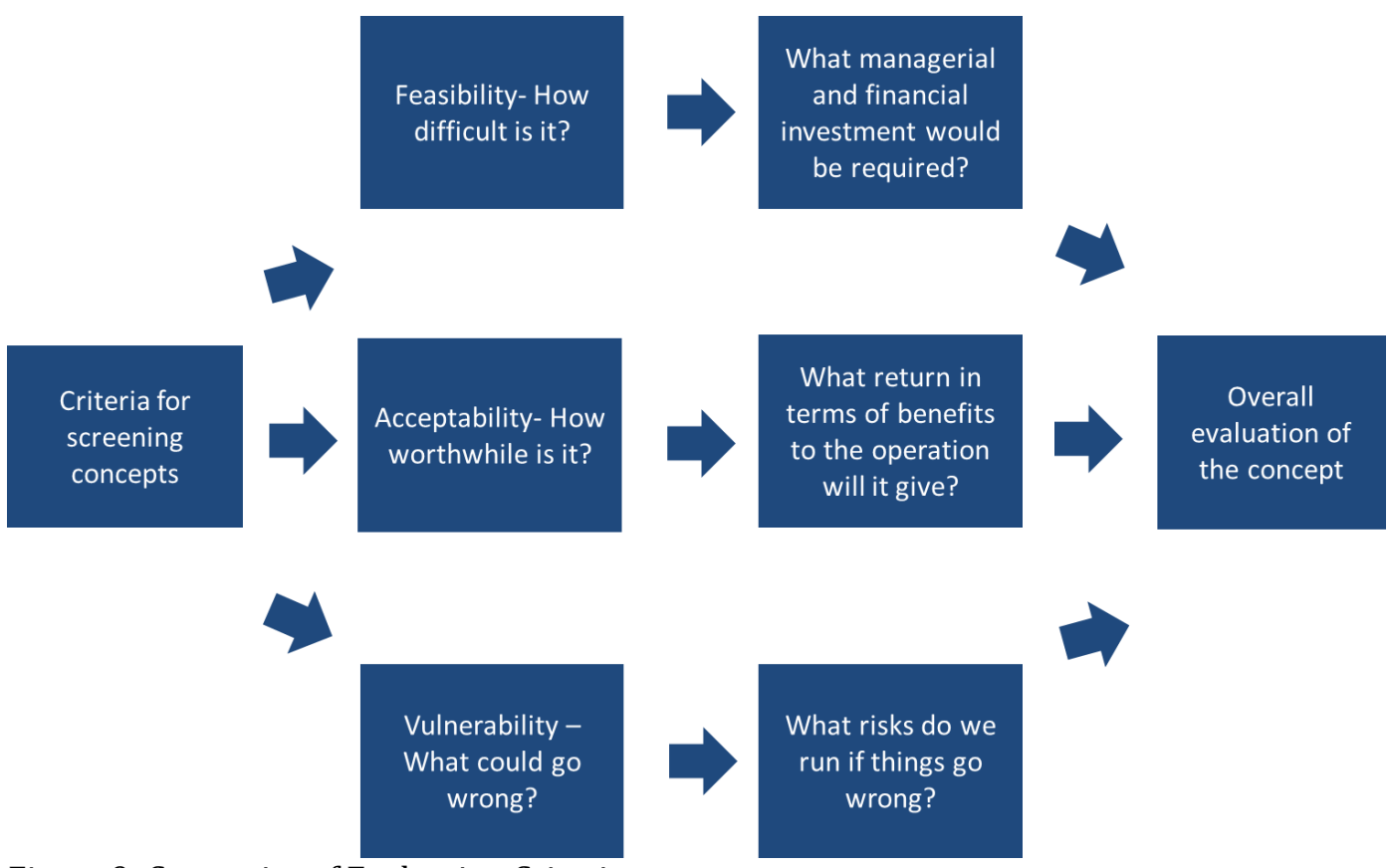

Figure 9: Categories of Evaluation Criteria

\section{Case Study}

At the turn of the page, Christopher aimed to type in a boisterous business buzz word. But no matter how many fancy phrases went in, his proposals did not win. Christopher worked 15 hours a day, despite frequently earning the wrath of his wife. Since his boss knew of the long hours Christopher spent, he could not understand why they were not winning deals.

So his boss decided to spend some budget and hire someone despite the financial crisis. After three months of head hunting, they realized they hired someone with essentially zero skills. How did that even happen? 


\section{Strategy 1: Changing Modus Operandi}

\section{Hiring Strategies}

Maybe interviews should be a thing of the past. With all the information available online nowadays, people can falsify resumes, pretend to be really good at interviews and fail miserably once they are working. For the team that is hiring them, it is a terrible waste of time, effort and capital.

Instead, it is advisable to ask prospective candidates to work on a demo proposal, if not a live proposal to assess their management proficiencies, writing abilities and evaluate how well they would fit into the team's environment. That would be a more wholistic approach to hiring proposal teams.

\section{Overcoming Workaholism}

Proposal Teams needs to consider if there are individual heroes who get overworked and pulled into every single "major deal" or get to find about it themselves and go vouch for it. IF that is the case, the team needs to consider if workaholism is going to become a problem in the long term. The typical workaholic ends up not sleeping and "burns the midnight oil". Unfortunately, the corporate system rewards them for it.

It takes a toll on the health of the individual in the long term, and at some point, the individual will experience burnout. In their book titled Rework, Fried and Hansson remark "Workaholics miss the point. They try to fix problems by throwing sheer hours at them. They try to make up for intellectual laziness with brute force. They even create crises. They do not look for ways to be more efficient because they actually like working overtime. They enjoy feeling like heroes. Workaholics are not heroes. They do not save the day. They just use it up. They may claim to be perfectionists but that just means that they are wasting time fixing inconsequential details instead of moving on to the next task" (Jason Fried, 2010)

\section{Workforce Training}

Most organisations we interviewed do not take proposal management seriously enough, and do not invest into training proposal management teams. While experience is a good thing, some theory can help teams remember what they may have forgotten or help them arrive at new ideas. It might allow proposal teams to reduce errors, improve proficiency, build confidence and increase overall team morale. This might enable the team to take a leap of excellence and possibly even increase organisational win ratios. Investing in trainings has become less expensive as most of them are happening virtually.

It is important to remind employees that learning new skills and sharpening existing ones is the only way to survive. Cal Newport argues in his bestselling book, "So Good They Can't Ignore You" that "skills trump passion in the quest for work one loves" (Newport, 2012). If organisations do not invest in them, employees need to take initiative and invest in themselves.

\section{Strategy 2: Kaizen-ing Proposal Management Strategies}

The word "strategy" is used in so many business meetings these days- a pause to think about the meaning of the word. The word has its origins in Greek. "Strategos" means "leading an army". Clearly, there is a military metaphor. It is intense and powerful. Today, it is a word that is almost borderline business jargon. 
With businesses finding themselves in such volatility today, effective business proposal strategy is essential.

\section{Having Any Plan Is Better Than Having No Plan}

It may be said that having any plan is better than having absolutely no plan, even if in hindsight, it proves to be the wrong plan. The following story is quoted by Slack and Lewis in their famous textbook for Operations Strategy:

A group of Hungarian soldiers got lost doing manoeuvres in the Alps. The weather was cold, and the snow was deep. In the freezing conditions, after two days of wandering, the soldiers gave up hope and became reconciled with a frozen death on the mountains. Then, much to their delight, one of the soldiers discovered a map in his pocket. Much cheered by the discovery, the soldiers were able to escape from the mountains. When they were safe back at their headquarters, they discovered that the map was not of the Alps but that of the Pyrenees. The moral of the story? A plan (or in this case, a map) may not be perfect, but it gives some sense of purpose and a sense of direction. If the soldiers had waited for the right map, they would have frozen to death. Yet, their renewed confidence motivated them to get up and create opportunities. (Slack, 2009)

\section{Conflicting Strategies}

Proposal strategies that conflict with one-another must be discussed and ironed out. For example, a proposal's strategy may be to increase organisational profitability. And in order to increase profitability, the organisation may choose to decide to outsource. Outsourcing decisions may improve profitability but must not hamper quality and reputability of output.

\section{Strategy 3: Infuse Clarity Into Proposals}

Over $77 \%$ proposal writers and managers think that the proposals they write are jargon-free and easy to read. Only $15 \%$ admit that they only do it when they have time.

A sample study into 30 proposals from 30 different authors has shown us that over $88 \%$ of proposals have complex jargon that does not explain itself and have a Flesch Reading Ease ${ }^{1}$ score of 10 or less, which proves that content is extremely complex, and authors just do not know how to measure and correct it. A poor writing style makes reading cumbersome.

Writers hope to persuade readers by adding jargon and business buzz words. However, organisations which had been responsible for introducing business jargon are now studying the effect of easy reading.

Deloitte studied thirty people in a Starbucks cafe who were given two documents each. One document was compiled with a lot of jargon and long sentences. The other was radically simple and easy to understand. Both were in effect- trying to share the same message.

Subjects read the two documents, and were given a list of character traits to associate each document with. The list of character traits had fifteen positive ("good") and fifteen negative ("bad") traits. The study found that $100 \%$ of the readers associated the document with jargon and complicated sentences with "obnoxiousness, rudeness, stubbornness and unreliability". Not a single positive trait was attributed to the complicated document. (Brian Fugere, 2005)

\footnotetext{
${ }^{1}$ Flesch Index scores range from 0-100. A Flesch Index of 0-10 indicates that the document is very hard to read and may at best be understood by university graduates.
} 
On the other hand, subjects who read the document without jargon did not associate it with even one negative trait. Instead, they associated with traits like "likability, energy, friendliness, inspirational and enthusiastic". Not a single negative trait was attributed to the document that was easy to read.
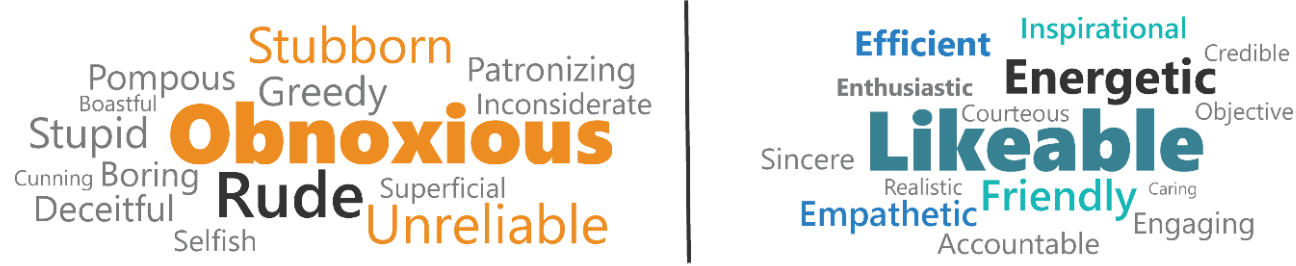

Figure 7: How Readability Influences Likeability

Donald Murphy, the editor of an agricultural newspaper found that reducing the complexity of his articles from a ninth grade to a sixth-grade level increased newspaper readership by $43 \%$ for an article on 'nylon'. There was an increase of 42,000 readers in a circulation of 275,000 . Reducing the complexity also caused a $60 \%$ increase in readership for an article on 'corn'. (Murali Mohana, 2016)

Easy reading increases readers' perseverance to complete reading the document. In the 1950s, Wilber Schramm, the director of Iowa Writer's Workshop interviewed 1,050 newspaper readers. He found that easier reading styles help decide how much of an article is read. He found that people read fewer long articles than short ones. A story nine paragraphs long will lose three out of ten readers by the fifth paragraph. A shorter story will lose only two. (Murali Mohana, 2016)

Studies like this transformed how American newspapers were written. Most American newspapers are now written at a 11th grade level. A cursory observation of popular novels shows that most of them are written at a 7th grade level. America's most sold publications TV Guide and Readers' Digest- are written at a 9th grade level. (Murali Mohana, 2016)

In summary, all research points to three things that are prime culprits for making reading difficult and must be avoided in proposals

The lack of logic and focus in writing

Jargon and complicated words

Long Sentences and endless paragraphs

\section{Conclusion}

Proposal management and writing are time-bound and mission-critical activities crucial to the survival of B2B business, and must involve the right people. Involving the wrong people to write a proposal is like asking a steward to fly a plane.

Organizations must hire the right people and train them. Proposal contributors must be able to write compelling content that sets them apart from competition. The presentation of their proposals must thoroughly delight readers. 
Proposal contributors must spend their time strategizing and not brooding over rudimentary tasks. They must be enabled with the process and technology required to do so.

We recommend that organizations adopt change gradually, and transform the way they manage, write and present proposals. Organizations must bid to win. Not just submit.

Consistent winning happens through effort and design. It is driven by purpose. If chemistry were to be used to give an analogy, one might say that there are no accidents that bring forth glorious proposals. Each element has to be weighed with precision and its relevance pondered upon. That defines the purity of the compound. Some elements must at all times be avoidedor the compound at the output would be worthless sludge. A complete waste of time, effort, and material of the chemist and not something of significance, beauty or worth.

We believe that effective proposal management and excellent proposal writing is not wishful thinking or a stroke of luck. We believe it needs to be cooked to perfection with a recipe- like a stew at a restaurant that people would want to visit over and over again.

The proposal must only have the right amount of persuasiveness for too much of it will sound suspicious. It must have sufficient evidence to back up claims. It needs to have clarity and not sound obnoxious. It needs to be managed well from end to end without getting anyone overworked (which is why training everyone is necessary).

Like a shrewd diplomat, a proposal emphasizes its strengths and benefits to its customer. In doing so, the proposal adds enough potent content that reveals a competitor's weaknesses and inadequacies.

Finally, it needs to be packaged well to invoke the emotion of persuasiveness and look like a work of meticulous, thoughtful and thought-provoking piece of art.

\section{Author Note}

This research paper and its presentation was funded in its entirety by Shipley Associates and was prepared for presentation at the International Conference on Social Sciences XVIII, to be held at the Oriel Congress Centre in the University of Cambridge

\section{Bibliography}

[1] Brian Fugere, C. H. (2005). Why Business People Speak Like Idiots. USA: Simon \& Schuster.

[2] Burnett, B. (2017, April 18). Introducting PointDrive. Retrieved from LinkedIn: https://www.linkedin.com/business/sales/blog/sales-navigator/introducingpointdrive

[3] Garner, B. A. (2012). HBR Guide to Better Business Writing. New York: Harvard Business Review Press.

[4] Gurnani, C. P. (2020, June 09). Covid crisis much worse than 2008 crisis. (P. Doval, Interviewer)

[5] Jason Fried, H. H. (2010). Rework. New York: Crown Publishing.

[6] Mark Kovac, J. C. (2018, November 1). Preparing for the Next Recession. Harvard Business Review, pp. 1-8. 
[7] Murali Mohana, N. (2016). Measuring the readability of newspapers a comparative study of two national english dailies. Mysore: University of Mysore.

[8] Newman, L. (2016). Shipley Proposal Guide 4.1 (Vol. 4.1). Kaysville, Utah: Shipley Associates.

[9] Newport, C. (2012). So Good They Can't Ignore You. London: Piatkus.

[10] Nicholas Toman, B. A. (2017). The New Sales Imperative. Harvard Business Review. Retrieved from https://hbr.org/2017/03/the-new-sales-imperative

[11] Pulizzi, J. (2014). Epic Content Marketing. New York: McGraw Hill Publications.

[12] Samik Roy, C. H. (2020, May 21). How Microsoft Teams is providing solutions to firms amidst the COVID crisis. (S. Chowdhary, Interviewer)

[13] Slack, N. (2009). Operations Strategy. In M. Lewis, Operations Strategy (2 ed.). UK: Pearson.

[14] Steven H Appelbaum, S. H.-L. (2012). Back to the Future: Revisiting Kotter's 1996 Change Model. Journal of Management Development, 31, 764-782. 